\title{
Numerical Modelling of Building Vibrations due to Railway Traffic: Analysis of the Mitigation Capacity of a Wave Barrier
}

\author{
Fran Ribes-Llario, Silvia Marzal, Clara Zamorano, and Julia Real \\ University Institute for Multidisciplinary Mathematics, Polytechnic University of Valencia, 46022 Valencia, Spain \\ Correspondence should be addressed to Fran Ribes-Llario; frarilla@cam.upv.es
}

Received 23 December 2016; Revised 15 March 2017; Accepted 2 April 2017; Published 18 April 2017

Academic Editor: Georges Kouroussis

Copyright ( 2017 Fran Ribes-Llario et al. This is an open access article distributed under the Creative Commons Attribution License, which permits unrestricted use, distribution, and reproduction in any medium, provided the original work is properly cited.

\begin{abstract}
Transmission of train-induced vibrations to buildings located in the vicinity of the track is one of the main negative externalities of railway transport, since both human comfort and the adequate functioning of sensitive equipment may be compromised. In this paper, a 3D FEM model is presented and validated with data from a real track stretch near Barcelona, Spain. Furthermore, a case study is analyzed as an application of the model, in order to evaluate the propagation and transmission of vibrations induced by the passage of a suburban train to a nearby 3-storey building. As a main outcome, vertical vibrations in the foundation slab are found to be maximum in the corners, while horizontal vibrations keep constant along the edges. The propagation within the building structure is also studied, concluding that vibrations invariably increase in their propagation upwards the building. Moreover, the mitigation capacity of a wave barrier acting as a source isolation is assessed by comparing vibration levels registered in several points of the building structure with and without the barrier. In this regard, the wave barrier is found to effectively reduce vibration in both the soil and the structure.
\end{abstract}

\section{Introduction}

The circulation of surface trains generates vibrations which are later propagated through the soil and transmitted to nearby buildings. This is becoming an issue of increasing relevance since it may cause nuisance to the people carrying out their activities there, as well as to originate the malfunctioning of sensitive equipment [1].

According to [2-4], vibrations propagate either as surface or as body waves. Among the first, compressional waves (or P-waves) induce particle motion parallel to the direction of propagation, while shear waves (or S-waves) generate perpendicular motion. Regarding surface waves, Rayleigh waves originate particle motion inside an elliptical vertical plane and decay more slowly with distance than body waves. The latter, together with the relevance of surface waves in the transmission process, as an order of magnitude, in the case of a vertical concentrated load, roughly $67 \%$ of the total excitation energy is transmitted through the soil by means of Rayleigh waves [4-6], making them a matter of major concern when assessing foundation isolation problems.
Moreover, high frequencies are particularly damped while propagating through the soil, which causes most part of the vibration spectrum arriving to a structure to be generally below $100 \mathrm{~Hz}$. The soil thus shifts the track vibrations to a range more probable to resonate with structures, since natural frequencies of most buildings are located below $10 \mathrm{~Hz}[3,4]$. Nevertheless, vibrations transmitted into buildings are highly dependent on the coupling between soil and foundation. In this regard, if there is an impedance mismatch between them, a significant part of the energy may be reflected at the soilstructure interface $[3,7]$.

Vibration assessment is a key aspect when analyzing the environmental impact of railway projects, especially for the case of urban railways, due to its proximity to buildings and the large number of stakeholders potentially involved. It is thus essential to deeply understand how vibrations propagate from the track to the building through the soil as well as how to implement the adequate mitigation measures in order to reduce the railway negative affection to buildings.

Several authors have approached this problem in the last decades by means of field studies as well as analytical and 
numerical modelling of the processes involved. Among the first group, [1] performed ground-borne vibration measurements in several buildings in the Boston area (originated by the passing of urban and subway trains) in order to analyze the transmission process through the ground to the foundation slab and within the building. In addition, [8] registered ground vibration induced by the passing of high speed trains over different earthwork profiles in Belgium and studied vibrations in three directions. From the analysis of the recorded data, the authors concluded that horizontal vibration levels might be as significant as the vertical ones, especially as the distance from the track increases. This is of relevance to numerical studies, since they generally focus on the prediction of vertical vibrations. Finally, the field work in [9] should also be highly remarked, since it presents an extensive database of ground vibration measurements made out of over 1500 high speed train registers from 7 different European countries. Within the study, the datasets are statistically analyzed and major conclusions are drawn regarding the effect of train speed and soil material properties (low and high significance, resp.), as well as the influence of soil critical speed, which is found to be very strong on the quasi-static excitation mechanisms.

Concerning analytical approaches, [10] developed a simple impedance-based mathematical model for the study of the dynamic behaviour of the building and its interaction with the ground, which was experimentally validated using a scaled building model. Additionally, [11] presented a fully analytical approach for an accurate calculation of the soil critical velocity with a low demand of computing resources. The authors then applied the model to analyze the influence of several parameters (e.g., ballast height, slab track characteristics, and soil conditions) on critical velocity.

On the other hand, among numerical modelling of the ground-borne vibration problem in buildings, several recent approaches may be highlighted. In this regard, [12] proposed a methodology for the calculation of railway-induced ground vibration transmission into buildings; $[13,14]$ developed a $2 \mathrm{D}$ finite element model to analyze the efficacy of trenches and elastic foundations in building vibration reduction; Ju $[15,16]$ used a 3D finite element model with absorbing boundary conditions to study vibration transmission to buildings near high speed lines, as well as the mitigation effect of wave barriers and soil improvement; [17] employed a 2D FEM model to assess the wave screening efficiency of different trench types on buildings; [18] investigated the effectivity of open and infilled trenches in reducing building vibration by means of a 2D FE-BE model; and [19] validated a 3D FEM model with field experiments and used it to analyze the effect of trench geometry in its shielding performance.

Other authors, such as [20], divide the noise and vibration problem into three weakly coupled subproblems (emission, transmission, and immission) and develop a specific model for each stage. First, the generation of vibrations at the railwheel interface is studied, assuming a large distance between track and building. Second, the previously obtained wave field is used as an excitation of a coupled soil-structure model. Structural vibrations are then calculated assuming that the acoustic field inside the building rooms does not influence wall vibrations. Lastly, the computed structural displacements are used as vibration input for the calculation of ground-borne noise in the building enclosures.

In a similar way, Kouroussis et al. $[5,21]$ presented and validated a numerical model dividing the process in two decoupled subsystems: (i) the vehicle-track-foundation interaction is analyzed by means of a 2D, 2-layer multibody model accounting for track irregularities; and (ii) the vibration propagation on the ground is reproduced on a 3D FEM model. To this aim, the reaction forces of the ballast obtained in the previous step are introduced as input loads acting at the ground surface. Such approach allows benefitting from the advantages of both techniques, namely, the short computation times of the 2D multibody model, the accuracy of 3D FEM modelling, and its ability to reproduce nonperiodic complex geometries. This model was successfully employed in [22] for studying simplified mathematical models of local irregularities (e.g., turnout, foundation transition, wheel flat, and rail joint).

Finally, the work of [23] shall be mentioned, which proposed a simplified numerical model consisting of three different submodels separately addressing each phase of the problem. Such approach was later validated in [24] by comparing the results with detailed numerical modelling (BEM + FEM formulation) and constitutes a simple, fast, and user-friendly tool providing reasonably accurate results for engineering purposes.

This paper analyzes the generation and transmission of train-induced vibrations to a nearby building, due to the passage of an urban railway. To this aim, a numerical 3D finite element model has been developed and validated, which is presented in Section 2. Then, the vibration transmission to a nearby building is studied in Section 3 and the efficiency of an infilled wave barrier as a mitigation measure is assessed in Section 4. Conclusions are drawn in Section 5.

\section{Description of the Model}

A 3D finite element model has been developed using the commercial software ANSYS LS-DYNA V17. It consists of two submodels that will be described separately within the section: the multibody system reproducing the vehicle and the track-soil-building model. It should be noted that this technique has been widely used for the numerical modelling of railway-induced building vibrations in the last years. In this regard, although they require a considerable computational effort, 3D FEM models are a very convenient and versatile technique, since they can easily and accurately reproduce complex and nonperiodical geometries $[6,21,22]$. The calibration and validation processes carried out with field data of a real train are also described in the final part of this section.

2.1. Multibody Vehicle Model. When studying railwayinduced vibrations both the vehicle and the track-soil-structure modelling should have a similar degree of complexity (i.e., the model should be globally simple or complex) [25]. Therefore, the vehicle has been reduced to a car body, two bogies, and four axles, which have been modelled as 
a three-dimensional multibody system. In this sense, although this technique requires a higher computational time, it also offers the highest accuracy [6]. According to [26], the vehicle's equation of motion can be reduced to

$$
\begin{aligned}
& {\left[\begin{array}{cccc}
\overline{M_{c}} & 0 & 0 & 0 \\
0 & \overline{M_{b}} & 0 & 0 \\
0 & 0 & \overline{M_{w}} & 0 \\
0 & 0 & 0 & 0
\end{array}\right]\left[\begin{array}{c}
\ddot{x}_{c} \\
\ddot{x}_{b} \\
\ddot{x}_{w} \\
\ddot{u}_{c}
\end{array}\right]} \\
& +\left[\begin{array}{cccc}
\overline{c_{2}} & -\overline{c_{2}} & 0 & 0 \\
-\overline{c_{2}} & \overline{c_{1}}+\overline{c_{2}} & -\overline{c_{1}} & 0 \\
0 & -\overline{c_{1}} & \overline{c_{1}} & 0 \\
0 & 0 & 0 & 0
\end{array}\right]\left[\begin{array}{l}
\dot{x}_{c} \\
\dot{x}_{b} \\
\dot{x}_{w} \\
\dot{u}_{c}
\end{array}\right] \\
& +\left[\begin{array}{cccc}
\overline{k_{2}} & -\overline{k_{2}} & 0 & 0 \\
-\overline{k_{2}} & \overline{k_{1}}+\overline{k_{2}} & -\overline{k_{1}} & 0 \\
0 & -\overline{k_{1}} & \overline{k_{1}} & 0 \\
0 & 0 & 0 & 0
\end{array}\right]\left[\begin{array}{l}
x_{c} \\
x_{b} \\
x_{w} \\
u_{c}
\end{array}\right] \\
& =\left[\begin{array}{c}
\overline{M_{a}} \\
\overline{M_{b}} \\
\overline{M_{w}} \\
0
\end{array}\right] g+\left[\begin{array}{c}
0 \\
0 \\
0 \\
F_{c}
\end{array}\right]
\end{aligned}
$$

where $\ddot{x}_{i}, \dot{x}_{i}$, and $x_{i}$ represent the acceleration, velocities, and displacements of the element denoted by the subscript $c$ (car body), $b$ (bogie), or $w$ (unsprung mass, i.e., wheelset); $M_{c}$, $M_{b}$, and $M_{w}$ are the total masses of each component (with $\left.\overline{M_{c}}=M_{c} / 4 ; \overline{M_{b}}=M_{b} / 2 ; \overline{M_{w}}=M_{w}\right) ; k_{i}$ and $c_{i}$ are the stiffness and damping of the primary $(i=1)$ and secondary $(i=2)$ suspension; $g$ is the gravity acceleration; $F_{c}$ represents the wheel-rail contact force; and $u_{c}$ is the rail displacement vector.

For the modelling of the different parts of the vehicle, 8 node hexahedral elements were selected for both car body and bogies; point elements were chosen for the wheels; and springs and dampers were selected for reproducing the primary and secondary suspension. The wheel/rail contact is modelled simulating a Hertzian spring $[26,27]$ and its interaction as a node-to-beam contact (allowing for sliding and loss of contact by means of the penalty algorithm). The track has been assumed to be in excellent conditions and therefore no roughness spectrum has been added to the rail. The latter shall not reduce significantly the accuracy of the model, since a short distance between track and building is considered and dynamic excitation (i.e., that caused by the rail unevenness) dominates the vibration levels in areas far from the track [9]. A full Newton-Raphson method has been employed for solving the nonlinear equations, while the transient dynamic equilibrium has been solved by means of a Newmark implicit time integration.
TABLE 1: Materials mechanical properties.

\begin{tabular}{lccc}
\hline & $E[\mathrm{MPa}]$ & $v[-]$ & $\rho\left[\mathrm{kg} / \mathrm{m}^{3}\right]$ \\
\hline Rail & 210.000 & 0.3 & 7500 \\
Rail pad & 150 & 0.45 & 900 \\
Sleeper & 27000 & 0.25 & 2400 \\
Ballast $^{*}$ & 100 & 0.2 & 1900 \\
Soil $^{*}$ & 150 & 0.3 & 2000 \\
Foundations & 1000 & 0.3 & 2000 \\
\hline *
\end{tabular}

2.2. Track-Soil-Building Model. The track, soil, building, and their components are represented as a mesh of hexahedral elements, whose maximum dimensions depend on the maximum wavelength, while the minimum size is set according to [28]. In every node of the mesh, (2) is solved:

$$
[M]\{\ddot{u}\}+[C]\{\dot{u}\}+[K]\{u\}=\{F(t)\},
$$

where $M, C$, and $K$ are the mass, damping, and stiffness matrixes, respectively; $\ddot{u}, \dot{u}$, and $u$ are the acceleration, velocity, and displacement vectors; and $F(t)$ is the vector of external forces, which introduces in this submodel the influence of the vehicle on the track.

In order to reduce the model complexity, it is commonly assumed that the effect of the train does not induce large strains in the soil (which is assumed to be nonlayered homogenous), and thus the displacements are limited to the elastic range in the stress-strain diagram. Such simplification is realistic, as shown in [8] for field measurements, and, therefore, material behaviour in this model has been assumed to be linear and elastic. The mechanical properties of the main elements of the model have been measured from the real track materials and are summarized in Table 1. For the modelling of the sleeper-ballast contact zone, bonded DOF's technique was used [29], which requires the introduction of duplicated nodes at the contact surface, one for each material. Between these nodes, the movement perpendicular to the contact plane is linked and therefore must move equivalently in such direction, while the movements parallel to the contact plane are not restricted.

The mechanical properties of those materials marked with an asterisk in Table 1, ballast and soil, have been obtained through a calibration process (i.e., by modifying their values within a realistic range and comparing the model results with the registered dataset). The rail pads have been modelled as 3D hexahedral elements according to [30] and a four-node connection with the rail.

Regarding the characteristics of the building, its dimensions are $9 \mathrm{~m}$ height, $13.5 \mathrm{~m}$ length (parallel to the track), and $9 \mathrm{~m}$ width (perpendicular to the track). The distance between the track and the building is $10 \mathrm{~m}$, and the threestorey structure is founded on a reinforced concrete slab with a thickness of $0.3 \mathrm{~m}$. The portal-frame structure is composed of columns and beams of identical cross section $(0.3 \times 0.3 \mathrm{~m})$, which support $0.3 \mathrm{~m}$ tick horizontal slabs on each floor. In the FEM model, the columns/beams are reproduced by BEAM188 elements and the slabs with Shell 181 


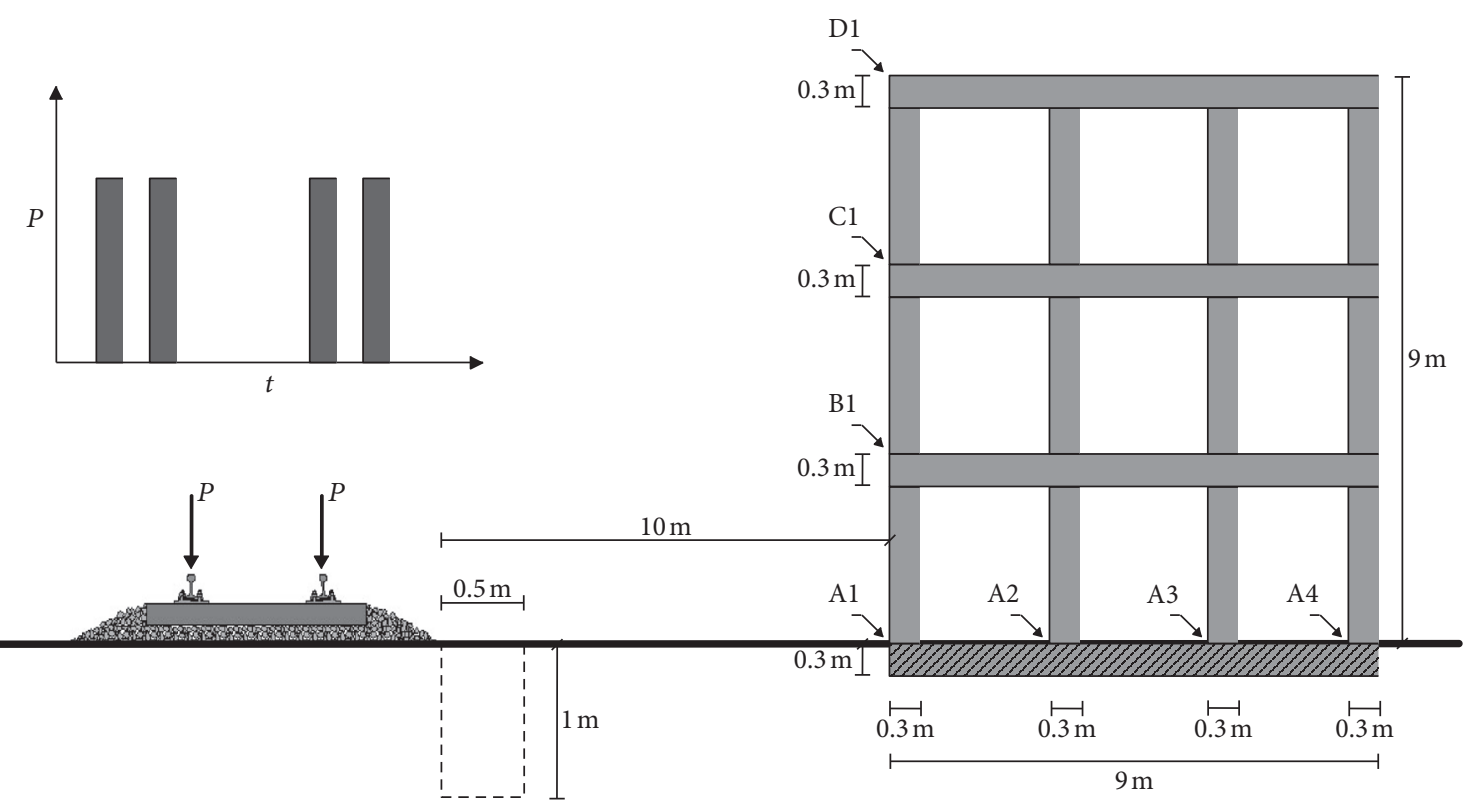

FIGURE 1: Scheme of the track-soil-building setup and the applied load.

elements. The maximum size of the elements is $0.1 \mathrm{~m}$, which accounts for the frequency range $(0-200 \mathrm{~Hz})$ considered in this paper. This range is sufficient to account for the relevant frequencies affecting buildings, which according to [10] is $8-80 \mathrm{~Hz}$. Figure 1 shows a detailed scheme of the track-soilbuilding numerical setup, with the wave barrier adjacent to the track (dashed line).

Regarding the model global dimensions, a total length (train running direction) of $X X . X \mathrm{~m}$ has been considered, thus accounting for $X X$ sleepers. On the other hand, the size in the cross-sectional directions is $X X \mathrm{~m}$ and $X X \mathrm{~m}$, respectively, which is enough to avoid boundary-related wave reflection problems (no absorbing boundaries have been used) and still ensures an acceptable computational cost [25, 31]. An overview of the global setup of the model is shown in Figure 2.

A modal analysis was performed in a first phase, in order to obtain the main vibration modes (see Figure 3). To this aim, damping was neglected and the external actions were disregarded. Consequently, (2) can be reduced to

$$
[M]\{\ddot{u}\}+[K]\{u\}=\{0\} .
$$

In the linear system considered, the free vibration is determined by harmonic functions as shown in

$$
\{u\}=\left\{\Phi_{i}\right\} \cos \left(\omega_{i} t\right),
$$

where $\Phi_{i}$ is the eigenvector associated with the mode shape of the $i$ th natural frequency $\omega_{i}$. Combining the previous equations, the modal analysis is performed by solving

$$
\left(-\omega_{i}^{2}[M]+[K]\right)\left\{\Phi_{i}\right\}=\{0\} .
$$

In this regard, the modes corresponding to low frequencies are both global torsional and bending modes of the whole

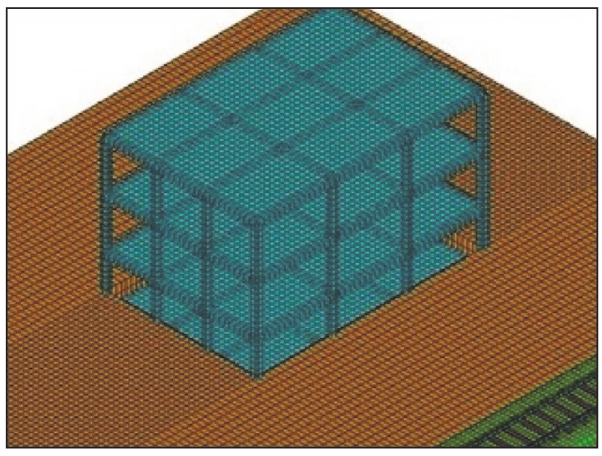

FIGURE 2: Detailed view of the FEM numerical model.

building. Nevertheless, for frequencies over $50 \mathrm{~Hz}$, the vibration modes correspond to the local bending modes of the floor slabs [20]. It should be noted that if the structure was much stiffer than the soil, it could be assumed that only the rigid body modes are excited at the structure foundation.

2.3. Calibration and Validation. Once the whole model is developed, its validity is assessed by comparing measured ground vibrations generated by the passage of a real train with those estimated by the model when the same conditions are reproduced. In order to obtain the real data, a gathering campaign was carried out, recording the vibrations induced by the passing of a FGC S-112 passenger train (Figure 4) in two different points of the track. Afterwards, two train pass-bys (running at $40 \mathrm{~km} / \mathrm{h}$ ) were selected; one for the calibration of the numerical model (i.e., estimation of the unknown track parameters) and the other for its validation.

The ballasted track stretch selected for this study is placed near the Sant Cugat del Vallès train station (Barcelona, Spain) and it is built over a vast layer of clays. In that stretch, the 


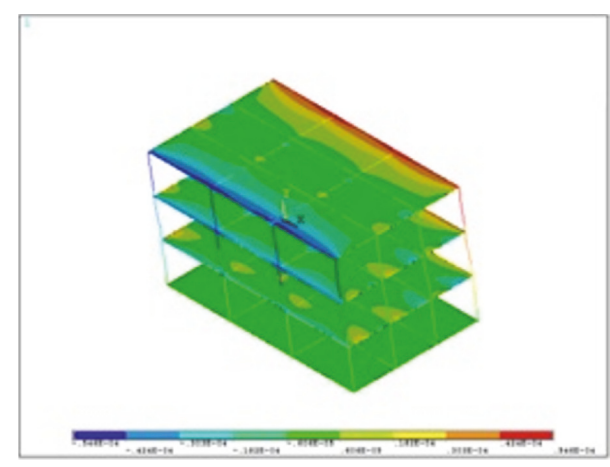

(a)

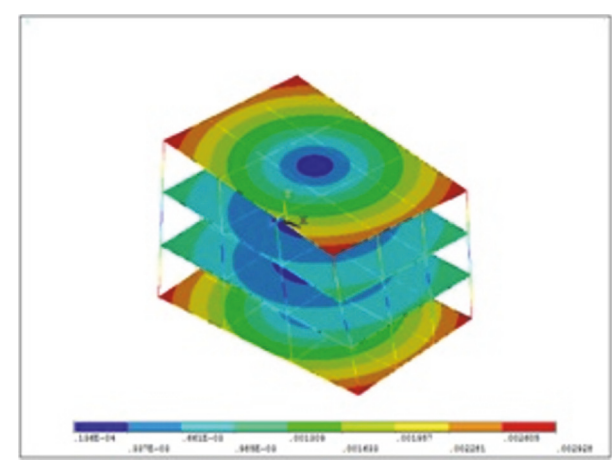

(b)

Figure 3: Building mode shapes at (a) $8.644 \mathrm{~Hz}$ and (b) $10.43 \mathrm{~Hz}$.

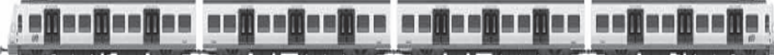

FIGURE 4: Composition of a FGC S-112 passenger train.

TABLE 2: Main characteristics of the vehicle.

\begin{tabular}{lc}
\hline$M_{c}[\mathrm{~kg}]$ & 34000 \\
$M_{b}[\mathrm{~kg}]$ & 4000 \\
$M_{w}[\mathrm{~kg}]$ & 1500 \\
$k_{h}[\mathrm{~N} / \mathrm{m}]$ & $2.8 \cdot 10^{9}$ \\
$k_{1}[\mathrm{~N} / \mathrm{m}]$ & $1.2 \cdot 10^{6}$ \\
$c_{1}[\mathrm{Ns} / \mathrm{m}]$ & $3 \cdot 10^{4}$ \\
$k_{2}[\mathrm{~N} / \mathrm{m}]$ & $0.55 \cdot 10^{6}$ \\
$c_{2}[\mathrm{Ns} / \mathrm{m}]$ & $9.8 \cdot 10^{4}$ \\
\hline
\end{tabular}

UIC-54 rails rest on concrete sleepers, with elastic rail pads in between. Regarding the considered vehicle, its main features are described in Table 2, where $k_{h}$ refers to the Hertzian contact stiffness.

For the aforementioned purposes, Sequoia FastTracer accelerometers $\left(0-2500 \mathrm{~Hz}\right.$ frequency range, $\pm 180 \mathrm{~m} / \mathrm{s}^{2}$ acceleration range) were used to measure vibration levels in two critical points of the track: the rail web and the sleeper surface. The field instrumentation layout is presented in Figure 5.

A comparison between the registered and calculated acceleration is shown in Figure 6 for validation, which indicates good agreement between model and real data, especially for peak values, in both the rail and the sleeper.

\section{Analysis of Results}

In order to evaluate the whole wave transmission process, vibration levels have been calculated in several key points through the propagation path (e.g., rail, sleeper, ground, and the edge of the building). Figure 7 presents a comparison between the acceleration generated in the rail-wheel contact (black) and those transmitted to the closest sleeper (grey) in both the time domain (a) and the frequency domain (b). As expected, the train-induced vibration is strongly attenuated (75\%) within this process.
After transmission to the sleepers, waves spread into the soil through the ballast layer, where additional attenuation is produced (90\%). However, once the waves propagate through the soil, the attenuation is much slower and decreases with distance. Figure 8 presents the vibrations reduction along their propagation path, in terms of soil particle acceleration and velocities.

As shown in Figure 8, vibrations are sharply mitigated along the first meters of the propagation path, especially in terms of particle acceleration, while, after that distance, the value seems to stabilize or even slightly increase.

The next step in the wave propagation path is the transmission from the soil to the nearby building foundations. In order to analyze this process, vertical and horizontal particle velocities and acceleration have been analyzed in four points on the foundation slab with increasing distance to the track (A1, A2, A3, and A4) and coincident with four building columns. The maximum registered values are shown in Figure 9.

As pointed out in Figure 9, horizontal vibrations are roughly constant along the edge of the slab both in terms of acceleration and velocities. On the contrary, the vertical values vary along the edge, being higher in the corners (points 1 and 4) than in the centre. Such behaviour is expected, since the slab presents very different structural stiffness on each direction (much higher in the horizontal plane than in the vertical one). Furthermore, the greater vertical vibration values on the corner points is also explained by the lower structural constraint of these points, when compared to the central ones.

A similar analysis has been carried out to evaluate how waves are transmitted from the foundation slab towards the top floor of the building. Therefore, vertical and horizontal vibrations have been calculated over the same vertical in different floors of the building ( $\mathrm{A} 1, \mathrm{~B} 1, \mathrm{Cl}$, and D1). The results are shown in Figure 10.

As presented in Figure 10, horizontal particle velocities considerably increase along their propagation path towards the top of the building, while vertical velocities and both vertical and horizontal particle acceleration are roughly constant. However, it can be concluded that vibrations are generally higher in the upper floors of the building, which is in agreement with previous studies such as [18]. 


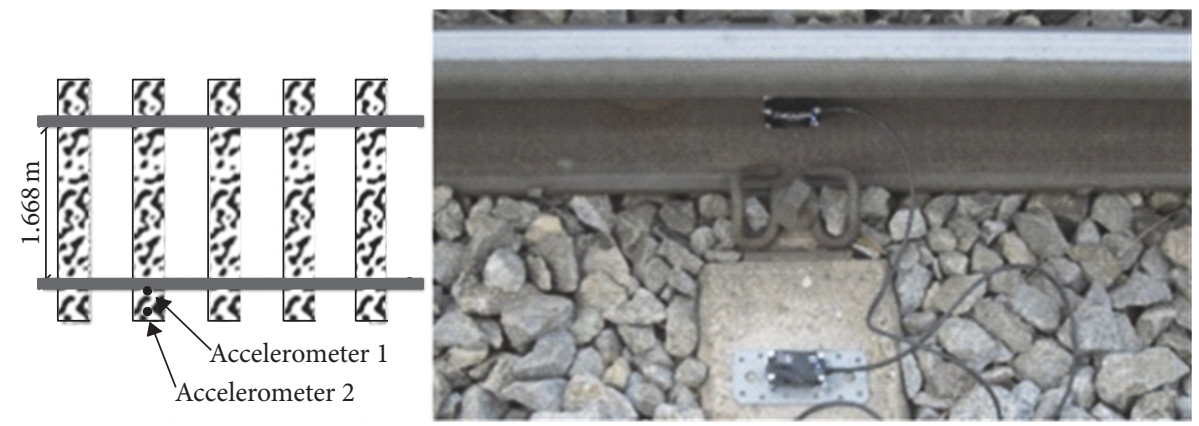

FigURE 5: Field instrumentation arrangement for the gathering campaign.

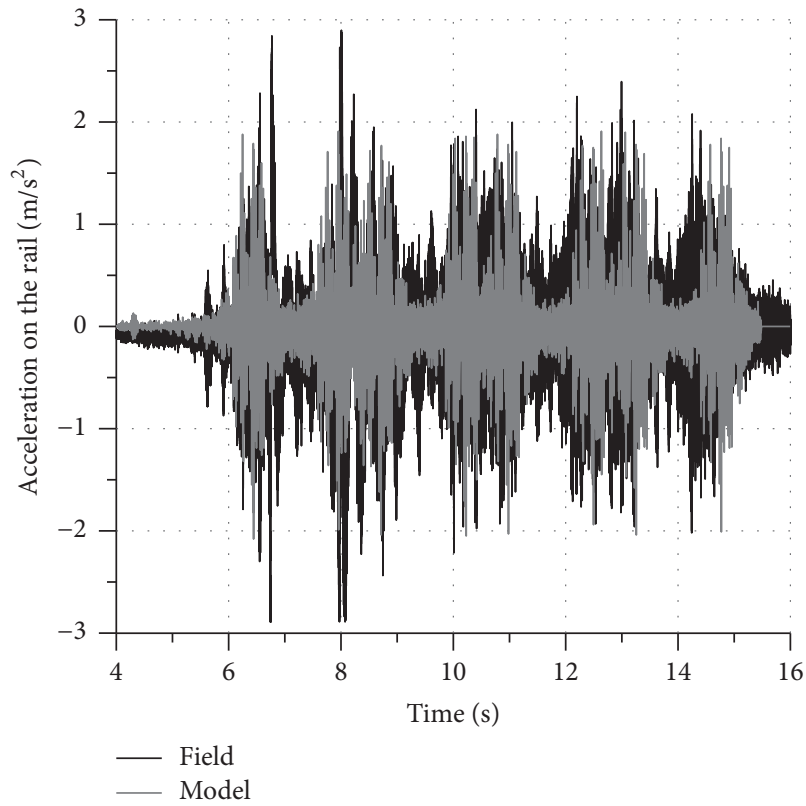

(a)

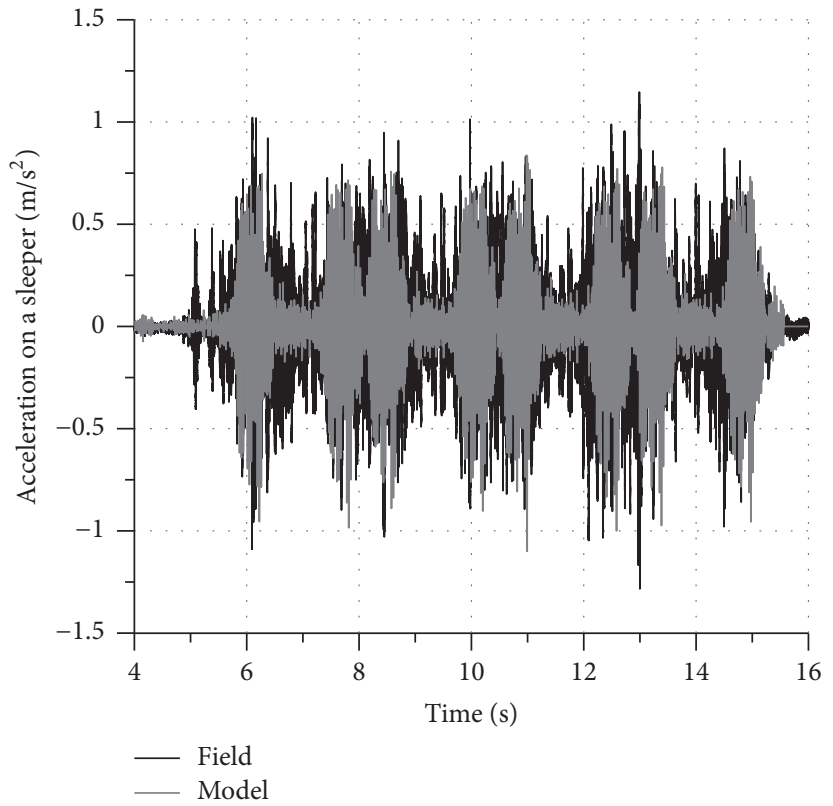

(b)

Figure 6: Vertical acceleration comparison between the model (grey) and field data (black). Results obtained on the rail (a) and over a sleeper (b).

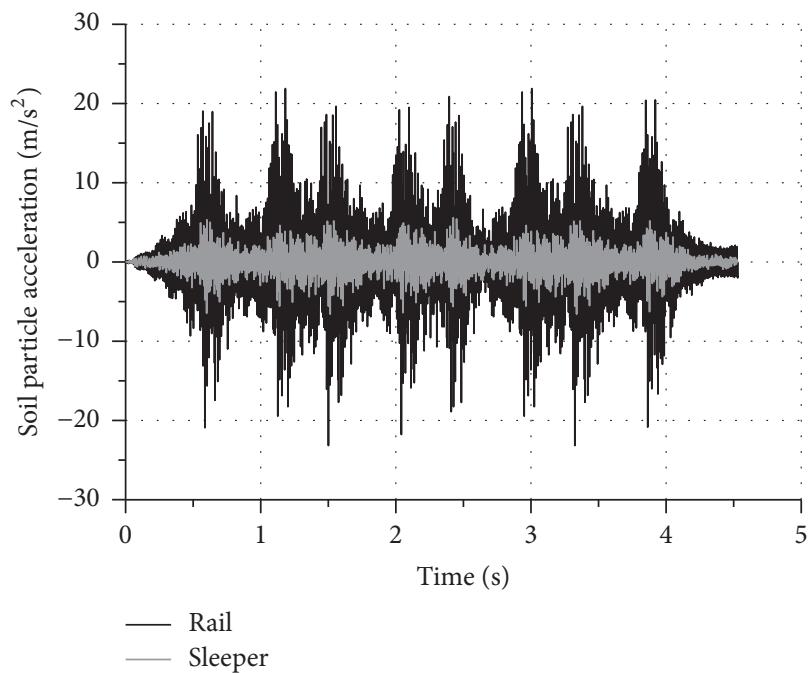

(a)

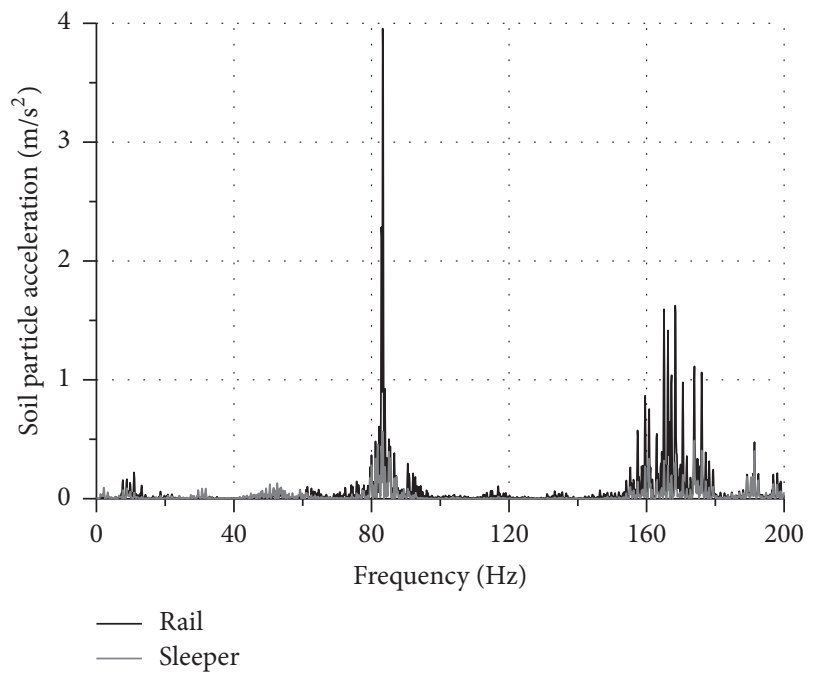

(b)

FIGURE 7: Acceleration comparison on the rail (black) and over a sleeper (grey). 


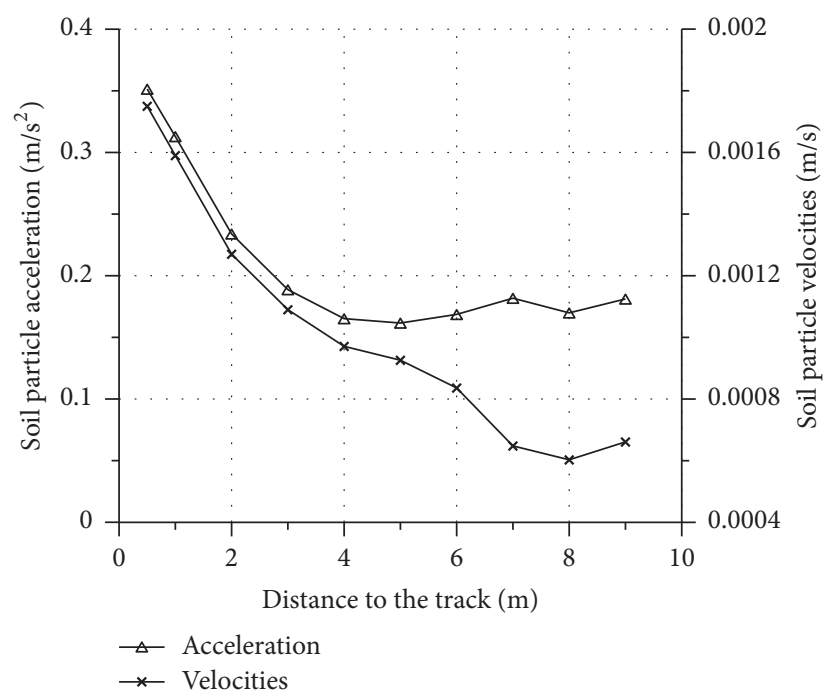

FIGURE 8: Soil particle acceleration and velocities at different distances to the track.

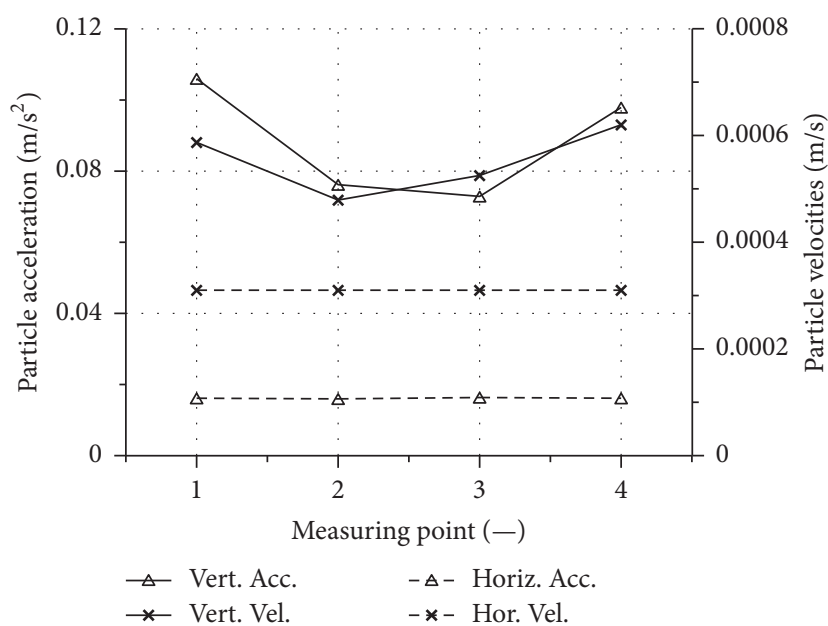

Figure 9: Vertical (solid line) and horizontal (dashed line) maximum acceleration and velocities on four different points of the foundation slab.

\section{Attenuation Effect of a Wave Barrier}

During last decades, many investigations have been focused on reducing the nuisance that railway-borne vibrations induce to people. In this regard, mitigation measures placed on the propagation path represent a cost-effective solution, in which no modifications to the track are required and multiple buildings can be protected simultaneously from vibrations. Within this type of measures, wave barriers represent one of the most common solutions.

Open trenches, which perfectly reflect waves [2], are the most effective type of wave barriers, but their construction in the soil is limited to shallow depths for stability reasons [32]. Unlike its width, which generally has lower influence [18, 19, 33], the depth of a trench highly affects its effectiveness: an increase of the trench depth clearly improves its shielding

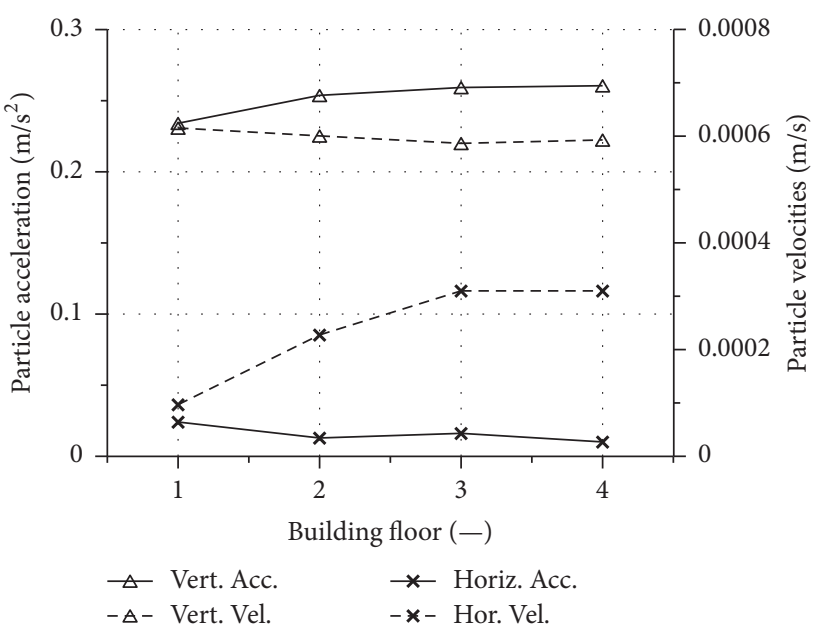

FIgURE 10: Vertical (solid line) and horizontal (dashed) maximum vibration velocities and acceleration in different floors of the building.

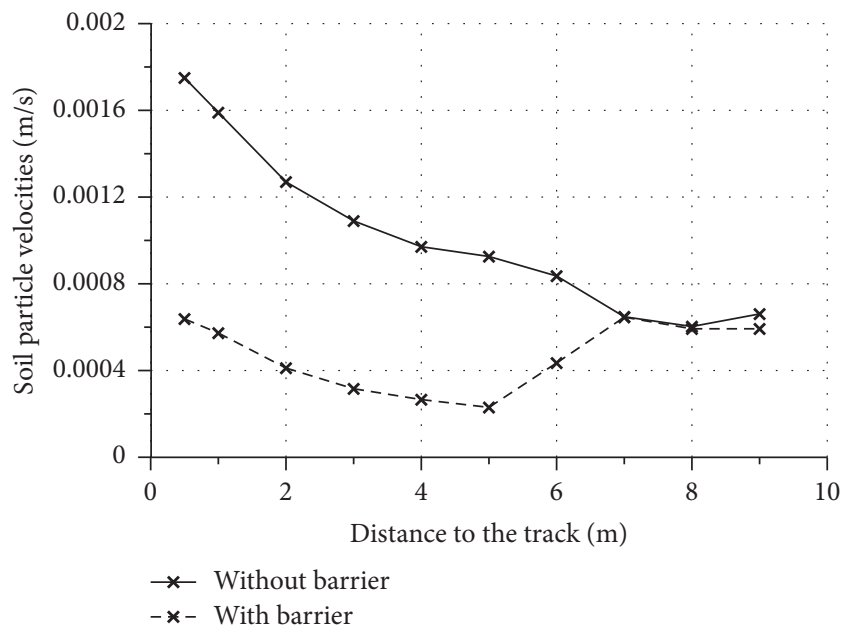

FIGURE 11: Soil vertical velocity with (dashed) and without (solid line) a wave barrier.

efficiency. Therefore, in order to achieve larger depths, infilled trenches are built using either soft (polystyrene and rubber chips) or stiff (concrete and grout) materials.

In this paper, a $0.5 \mathrm{~m}$ width, $1 \mathrm{~m}$ depth $\left(\approx 0.5 \cdot \lambda_{R}\right)$ EPS infilled trench is modelled according to [34], adjacent to the track as depicted in Figure 1; and its shielding capacity is evaluated in several points of the propagation path. The trench is located adjacent to the track, thus acting as an active isolation barrier. Figure 11 presents the soil particle vertical velocity along the propagation path, considering both the absence (solid line) and presence (dashed) of a wave barrier. It shows a significant vibration decrease (more than 60\%) in the section adjacent to the track if a wave barrier is built. However, this attenuating effect decreases with distance and is even neutralised close to a distance of $7 \mathrm{~m}$ from the track. The latter may be due to a wave reflection from the foundation slab. 


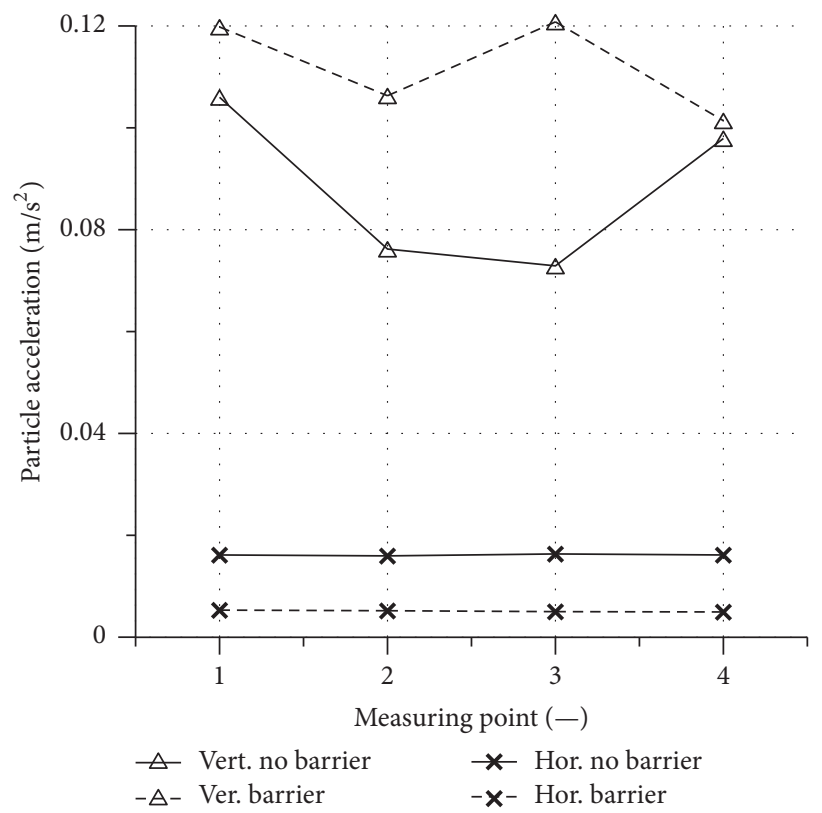

(a)

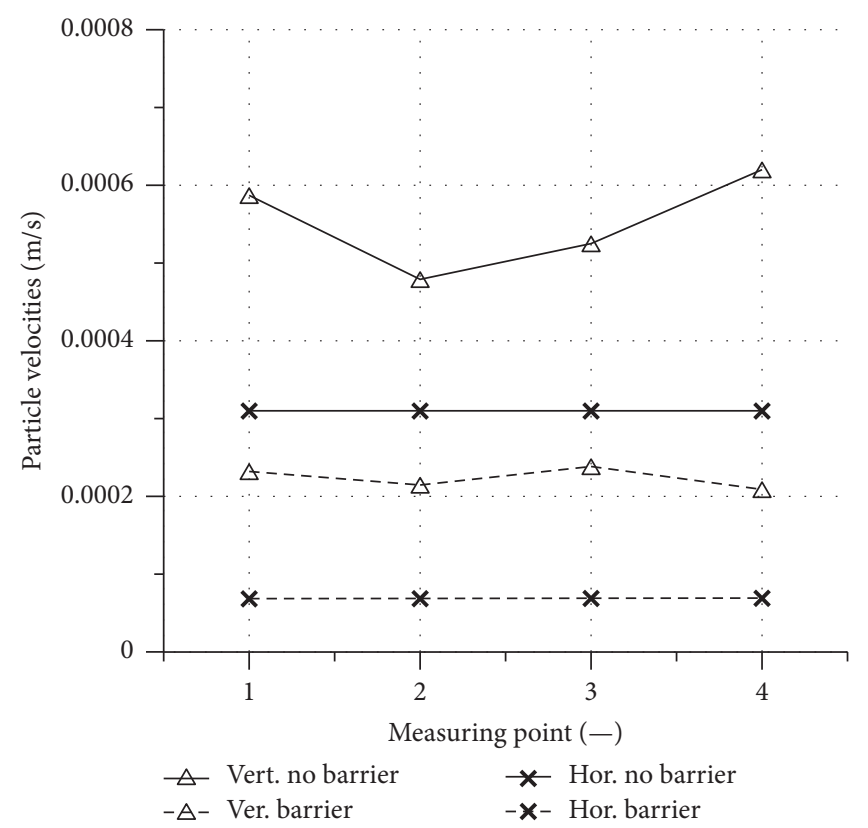

(b)

FIGURE 12: Maximum particle velocities and acceleration on several points of the foundation slab with (dashed line) and without (solid line) a wave barrier.

Furthermore, although the vibrations registered in the soil near the building presented similar values for both scenarios, there are significant differences when different points of the foundation slab are analyzed. As shown in Figure 12, a substantial reduction (more than 50\%) in vertical and horizontal velocities occurs when the wave barrier is installed, as well as in horizontal acceleration.

This phenomenon may be influenced by the frequency at which waves are propagated through the soil in each case (with and without the barrier), since the vibration transmission between soil and foundation depends not only on the mechanical characteristics of both materials but also on the frequency of the transmitted wave. Figure 13 shows the frequency spectrum in the foundation slab for both cases.

As illustrated in Figure 13, low-frequency $(0-50 \mathrm{~Hz})$ vertical vibrations are filtered when the construction of a wave barrier is considered. The natural frequencies of the structure are precisely within that mitigated range $(2-10 \mathrm{~Hz})$, which leads to a weaker transmission from the soil to the foundation slab. Furthermore, with the installation of an infilled trench, the differences between the calculated particle velocities on the centre and the corners of the slab are reduced. Nevertheless, vertical acceleration on the slab presents a different behaviour, increasing when the barrier is built. Such tendency may respond to an interference between incident and reflected waves related to the distance between building and barrier, as pointed out by [18].

Finally, regarding the transmission of waves towards the top of the building, it can be concluded that the presence of a wave barrier significantly reduces both velocities and acceleration in the building (see Figure 14), except for the first floor (foundation slab) where the abovementioned effect of wave interference is more relevant. Moreover, the vibration reduction is considerably higher for vertical vibrations and maintains constant upwards the building, keeping thus higher vibration rates on the upper floors.

\section{Conclusions}

In this paper, the influence of railway-borne vibrations on a nearby building has been studied. The analysis has been carried out on several critical points of the propagation path, including the track, the building, and the soil between them. Moreover, the transmission to the foundation and propagation within the structure has also been evaluated. As a result of such analysis, the following conclusions are drawn:

(i) Vertical vibrations on the foundation slab vary along the edge, being higher on the corners due to lower structural constraints.

(ii) Horizontal vibrations are roughly constant along de edge of the foundation slab.

(iii) Horizontal particle velocities considerably increase upwards the building, while vertical ones and acceleration keep roughly constant. Therefore, it can be concluded that vibrations are invariably higher in the upper floors of the building.

Furthermore, the influence of an infilled wave barrier placed next to the track has been assessed along the wave propagation path and within the building, leading to the following conclusions:

(i) Vibrations are substantially reduced in the soil along the propagation path because of the presence 


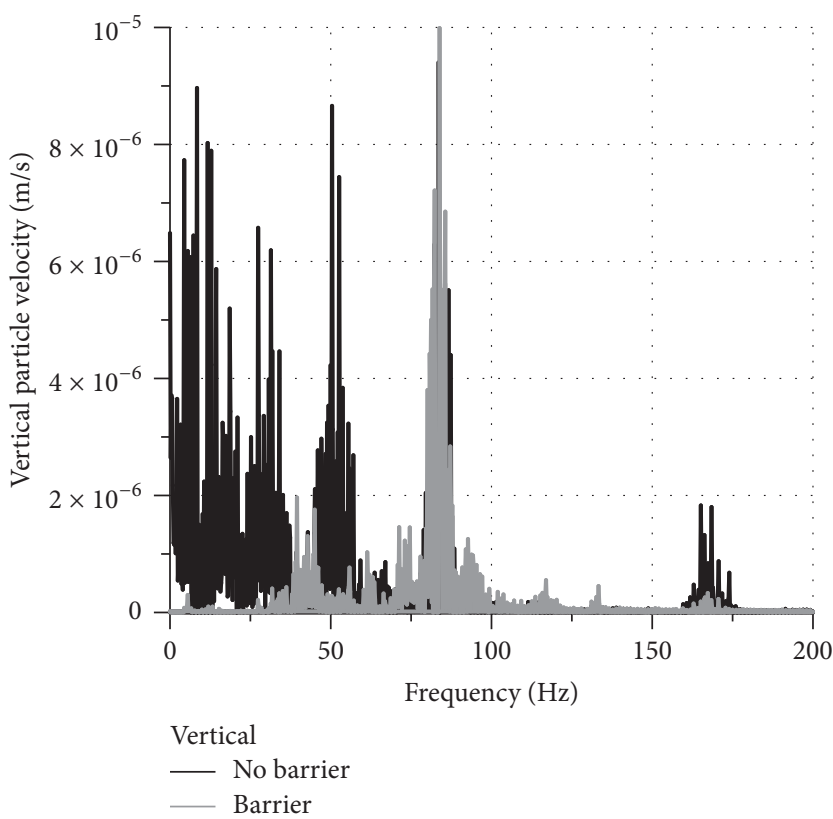

(a)

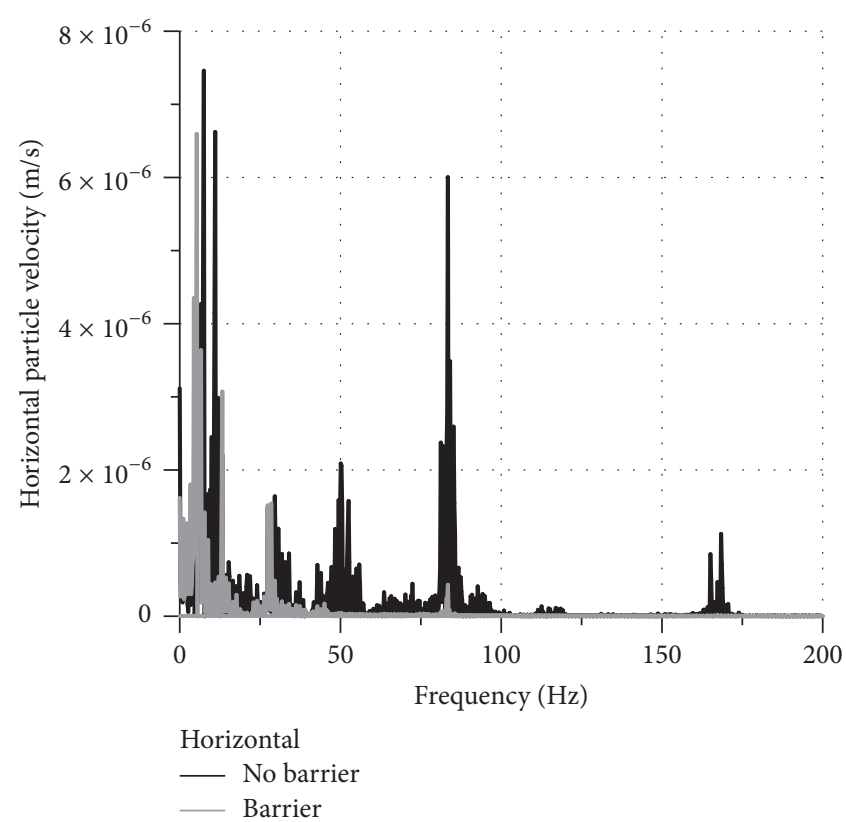

(b)

FigURE 13: Spectral comparison of vertical vibrations in the foundation slab with (grey) and without (black) a wave barrier.

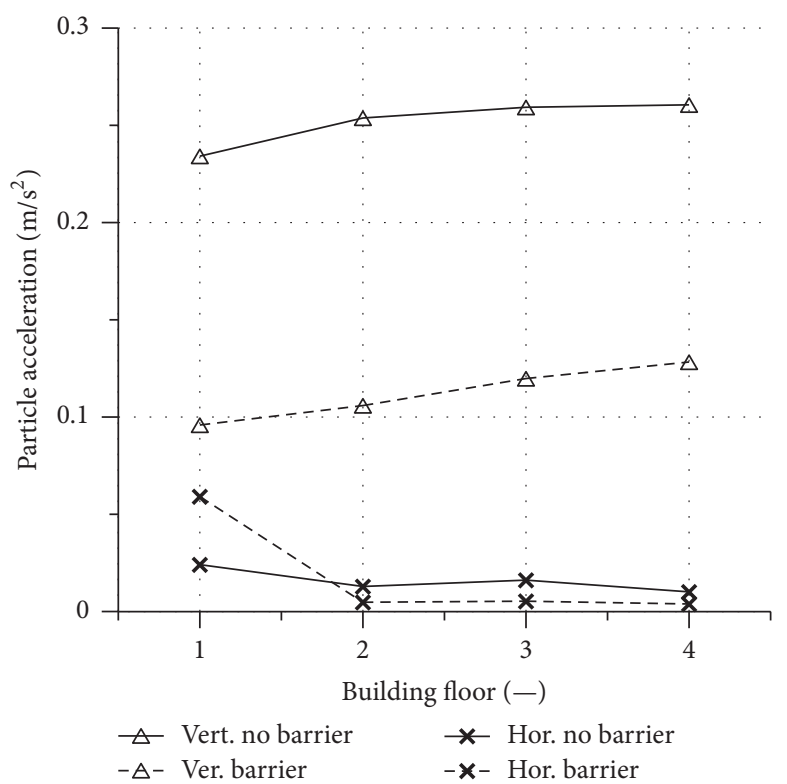

(a)

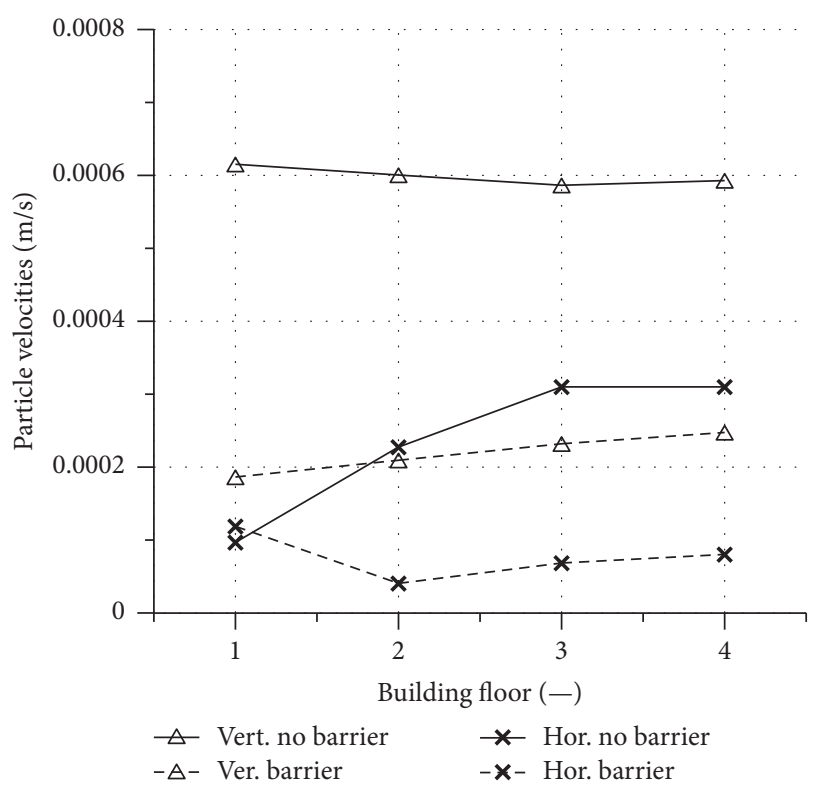

(b)

FIGURE 14: Maximum particle velocities and acceleration in different floors with (dashed line) and without (solid line) a wave barrier.

of the barrier, especially in the vicinity of the track.

(ii) The trench significantly reduces the particle velocity on the foundation slab, although the vertical acceleration may be increased due to an interference between incident and reflected waves. It will strongly depend on the distance between building and trench, as well as on the transmitted frequency. (iii) The presence of a wave barrier considerably reduces the vibrations transmitted to the upper floors of the structure

\section{Conflicts of Interest}

The authors declare that there are no conflicts of interest regarding the publication of this paper. 


\section{References}

[1] M. Sanayei, P. Maurya, and J. A. Moore, "Measurement of building foundation and ground-borne vibrations due to surface trains and subways," Engineering Structures, vol. 53, pp. 102-111, 2013.

[2] R. D. Woods, "Screening of surface waves in soils," Soil Mechanics and Foundations, vol. 94, pp. 951-979, 1968.

[3] A. Eitzenberg, Train-induced Vibrations in Tunnels: A Review, Lulea University of Technology: Lulea, Sweden, 2008.

[4] D. P. Connolly, G. Kouroussis, O. Laghrouche, C. L. Ho, and M. C. Forde, "Benchmarking railway vibrations-track, vehicle, ground and building effects," Construction and Building Materials, vol. 92, article no. 5718, pp. 64-81, 2014.

[5] G. Kouroussis, L. van Parys, C. Conti, and O. Verlinden, "Using three-dimensional finite element analysis in time domain to model railway-induced ground vibrations," Advances in Engineering Software, vol. 70, pp. 63-76, 2014.

[6] G. Kouroussis, D. P. Connolly, and O. Verlinden, "Railwayinduced ground vibrations-a review of vehicle effects," International Journal of Rail Transportation, vol. 2, no. 2, pp. 69-110, 2014.

[7] P. Remington, L. Kurzweil, and D. Tower, Low-frequency noise and vibrations from trains, Butterworths, London, UK, 1987.

[8] D. P. Connolly, G. Kouroussis, P. K. Woodward, P. Alves Costa, O. Verlinden, and M. C. Forde, "Field testing and analysis of high speed rail vibrations," Soil Dynamics and Earthquake Engineering, vol. 67, pp. 102-118, 2014.

[9] D. P. Connolly, P. Alves Costa, G. Kouroussis, P. Galvín, P. K. Woodward, and O. Laghrouche, "Large scale international testing of railway ground vibrations across Europe," Soil Dynamics and Earthquake Engineering, vol. 71, pp. 1-12, 2015.

[10] M. Sanayei, N. Zhao, P. Maurya, J. A. Moore, J. A. Zapfe, and E. M. Hines, "Prediction and mitigation of building floor vibrations using a blocking floor," Journal of Structural Engineering (United States), vol. 138, no. 10, pp. 1181-1192, 2012.

[11] S. B. Mezher, D. P. Connolly, P. K. Woodward, O. Laghrouche, J. Pombo, and P. A. Costa, "Railway critical velocity-Analytical prediction and analysis," Transportation Geotechnics, vol. 6, pp. 84-96, 2016.

[12] H. E. M. Hunt, "Modelling of rail vehicles and track for calculation of ground-vibration transmission into buildings," Journal of Sound and Vibration, vol. 193, no. 1, pp. 185-194, 1996.

[13] Y.-B. Yang and H.-H. Hung, "A parametric study of wave barriers for reduction of train-induced vibrations," International Journal for Numerical Methods in Engineering, vol. 40, no. 20, pp. 3729-3747, 1997.

[14] H. H. Hung, Y. B. Yang, and D. W. Chang, "Wave barriers for reduction of train-induced vibrations in soils," Journal of Geotechnical and Geoenvironmental Engineering, vol. 130, no. 12, pp. 1283-1291, 2004.

[15] S. H. Ju, "Three-dimensional analyses of wave barriers for reduction of train-induced vibrations," Journal of Geotechnical and Geoenvironmental Engineering, vol. 130, no. 7, pp. 740-748, 2004.

[16] S. H. Ju, "Finite element analysis of structure-borne vibration from high-speed train," Soil Dynamics and Earthquake Engineering, vol. 27, no. 3, pp. 259-273, 2007.

[17] M. H. El Naggar and A. G. Chehab, "Vibration barriers for shock-producing equipment," Canadian Geotechnical Journal, vol. 42, no. 1, pp. 297-306, 2005.
[18] M. Adam and O. Von Estorff, "Reduction of train-induced building vibrations by using open and filled trenches," Computers and Structures, vol. 83, no. 1, pp. 11-24, 2005.

[19] D. Connolly, A. Giannopoulos, W. Fan, P. K. Woodward, and M. C. Forde, "Optimising low acoustic impedance back-fill material wave barrier dimensions to shield structures from ground borne high speed rail vibrations," Construction and Building Materials, vol. 44, pp. 557-564, 2013.

[20] P. Fiala, G. Degrande, and F. Augusztinovicz, "Numerical modelling of ground-borne noise and vibration in buildings due to surface rail traffic," Journal of Sound and Vibration, vol. 301, no. 3-5, pp. 718-738, 2007.

[21] G. Kouroussis, L. Van Parys, C. Conti, and O. Verlinden, "Prediction of ground vibrations induced by urban railway traffic: an analysis of the coupling assumptions between vehicle, track, soil, and buildings," International Journal of Acoustics and Vibrations, vol. 18, no. 4, pp. 163-172, 2013.

[22] G. Kouroussis, D. P. Connolly, G. Alexandrou, and K. Vogiatzis, "The effect of railway local irregularities on ground vibration," Transportation Research Part D: Transport and Environment, vol. 39, pp. 17-30, 2015.

[23] L. Auersch, "Building response due to ground vibrationsimple prediction model based on experience with detailed models and measurements," International Journal of Acoustics and Vibrations, vol. 15, no. 3, pp. 101-112, 2010.

[24] L. Auersch, A. Romero, and P. Galvín, "Respuesta dinámica de edificaciones producida por campos de ondas incidentes considerando la interacción suelo-estructura," Revista Internacional de Métodos Numéricos para Cálculo y Diseño en Ingeniería, vol. 30, no. 4, pp. 256-263, 2014.

[25] R. Sañudo, L. dell'Olio, J. A. Casado, I. A. Carrascal, and S. Diego, "Track transitions in railways: a review," Construction and Building Materials, vol. 112, pp. 140-157, 2016.

[26] P. Galvín, A. Romero, and J. Domínguez, "Fully threedimensional analysis of high-speed traintracksoil-structure dynamic interaction," Journal of Sound and Vibration, vol. 329, no. 24, pp. 5147-5163, 2010.

[27] P. Antolín, N. Zhang, J. M. Goicolea, H. Xia, M. Á. Astiz, and J. Oliva, "Consideration of nonlinear wheel-rail contact forces for dynamic vehicle-bridge interaction in high-speed railways," Journal of Sound and Vibration, vol. 332, no. 5, pp. 1231-1251, 2013.

[28] J. I. Real, C. Zamorano, C. Hernández, R. Comendador, and T. Real, "Computational considerations of 3-D finite element method models of railway vibration prediction in ballasted tracks," Journal of Vibroengineering, vol. 16, no. 4, pp. 1709-1722, 2014.

[29] I. Gallego, A. Rivas, S. Sanchez-Cambronero, and J. Lajara, "Dynamic modelling of high speed ballasted railway tracks: analysis of the behaviour," Transportation Research Procedia, vol. 18, pp. 357-365, 2016.

[30] L. Montalbán, J. Real, and T. Real, "Mechanical characterization of railway structures based on vertical stiffness analysis and railway substructure stress state," Proceedings of the Institution of Mechanical Engineers, Part F: Journal of Rail and Rapid Transit, vol. 227, no. 1, pp. 74-85, 2013.

[31] J. Real-Herráiz, C. Zamorano-Martín, T. Real-Herráiz, and S. Morales-Ivorra, "New transition wedge design composed by prefabricated reinforced concrete slabs," Latin American Journal of Solids and Structures, vol. 13, no. 8, pp. 1431-1449, 2016.

[32] P. Coulier, V. Cuéllar, G. Degrande, and G. Lombaert, "Experimental and numerical evaluation of the effectiveness of a 
stiff wave barrier in the soil," Soil Dynamics and Earthquake Engineering, vol. 77, pp. 238-253, 2015.

[33] L. Andersen and S. R. K. Nielsen, "Reduction of ground vibration by means of barriers or soil improvement along a railway track," Soil Dynamics and Earthquake Engineering, vol. 25, no. 7-10, pp. 701-716, 2005.

[34] J. I. Real, C. Zamorano, and F. Ribes, "Wave barriers for the reduction of railway induced vibrations. Analysis in tracks with geometric restrictions," Journal of Vibroengineering, vol. 16, no. 6, pp. 2821-2833, 2014. 


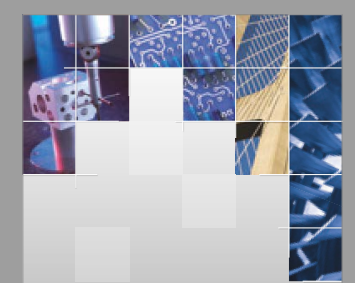

\section{Enfincering}
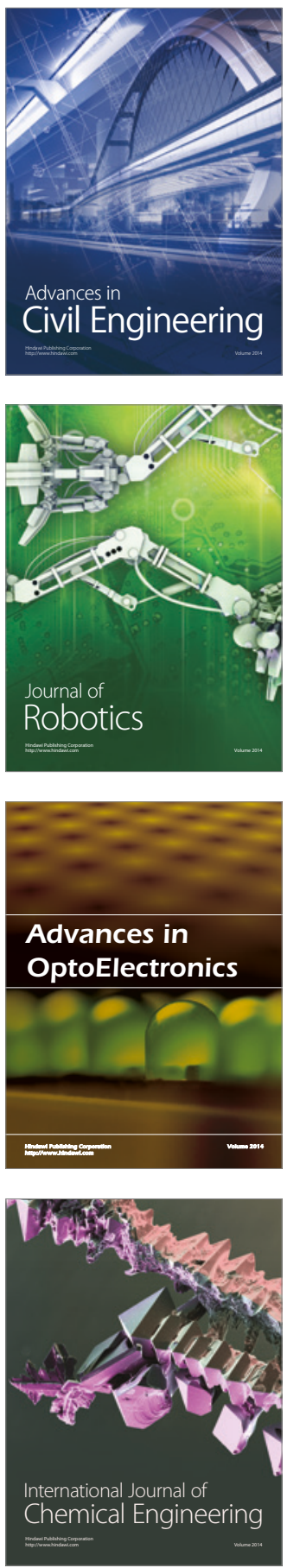

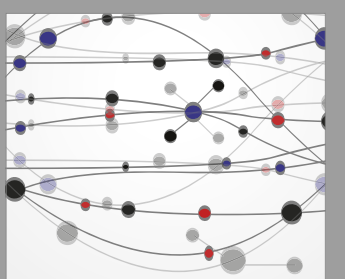

The Scientific World Journal

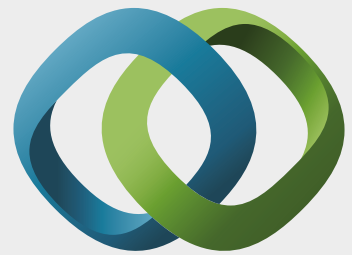

\section{Hindawi}

Submit your manuscripts at

https://www.hindawi.com
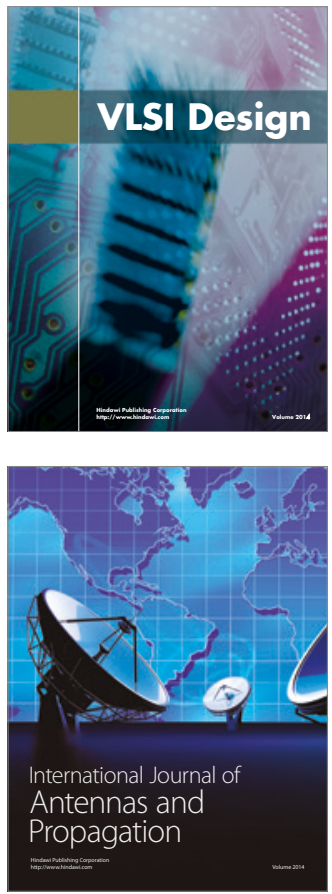

\section{Rotating}

Machinery
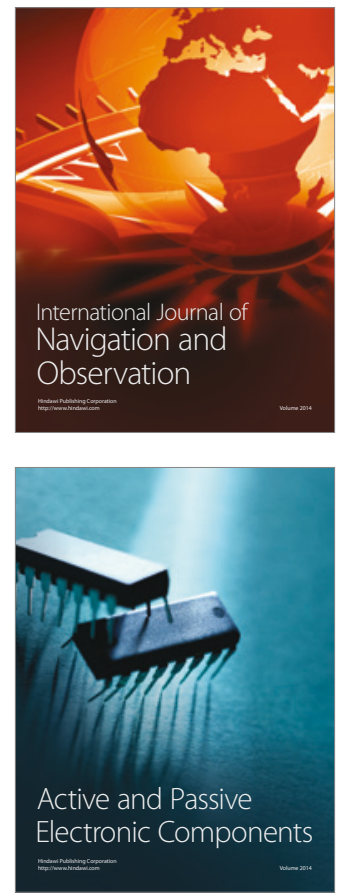
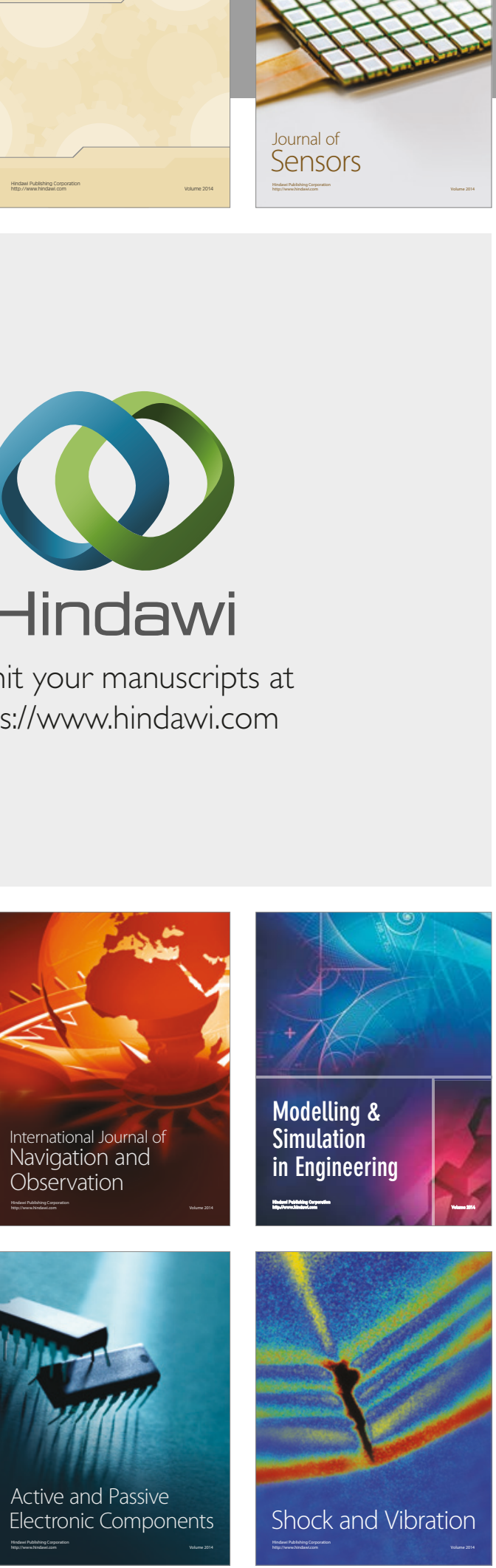
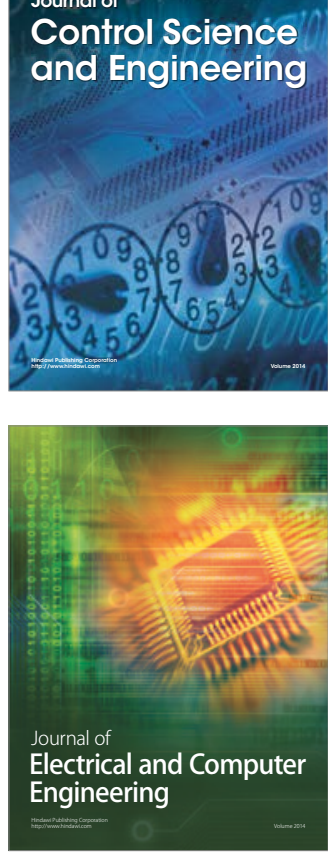

Distributed

Journal of

Control Science

and Engineering
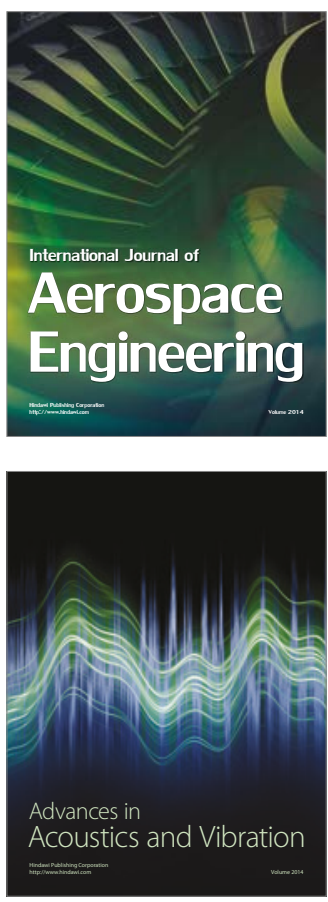

Sensor Networks 